\title{
“FOLIA DE REIS" EM MINAS GERAIS COMO RITUAL RELIGIOSO, FESTA POPULAR E PATRIMÔNIO IMATERIAL
}

\author{
"FOLIA DE REIS" IN MINAS GERAIS AS RELIGIOUS RITUAL, POPULAR PARTY \\ AND IMMATERIAL HERITAGE
}

\author{
André Luis Santos de Souza ${ }^{1}$ e André Luiz Ribeiro de Araújo² \\ ${ }^{1}$ Doutorando e Mestre em Antropologia Social pelo PPGAS-Museu Nacional/UFRJ; licenciado e \\ bacharel em Ciências Sociais pela Universidade Federal de Viçosa/UFV; E-mail: \\ andreconatus@gmail.com, ORCID: https://orcid.org/0000-0002-5293-816X
}

2 Doutorando do Programa de Pós-graduação em História pela Universidade Federal de Juiz de Fora;
Mestre em Pós-Graduação Interdisciplinar em Artes, Urbanidades e Sustentabilidade da Universidade
Federal de São João Del-Rei; Licenciado e bacharel em História pela Universidade Federal de
Viçosa/UFV, E-mail: andreclassrock@hotmail.com

A R T I C LE IN F O

Article history:

Received 2020-02-14

Accepted 2020-06-20

Available online 2020-06-20
Palavras-chave: Folia de Reis. Narrativa Mítica. Ritual Religioso. Mitopráxis. Performance.

Keywords: Folia de Reis. Mythical Narrative. Religious Ritual. Mitopráxis. Performance.

RESUMO: O presente artigo é fruto de um estudo sistemático com base em metodologias, técnicas e estratégias de pesquisa da História e da Antropologia Social. Parte-se da mobilização documental e da vivência cotidiano entre um grupo de foliões que praticam a Folia de Reis de Carlos Chagas (MG). O objetivo foi analisar o núcleo motivacional presente na performance dos foliões. Destacou-se a narrativa mítica encarnada nas "passadas" durante a "vivência mítica" (mitopráxis) da Festa da Folia. A partir daí foi possível analisar os elementos simbólicos ligados aos eventos bíblicos relativos ao nascimento do menino Jesus. Tais elementos apareciam nas performances dos foliões durante o ritual da Folia. Este ritual rememora passagens bíblicas e ainda promove prestações, contraprestações entre os praticantes direta e indiretamente, e devoções ao Santo. A Folia de Reis, além de uma festa religiosa, um patrimônio imaterial, também é um tipo de ritual ligado à cosmologia do sistema religioso católico praticado na região mineira estudada há mais de um século.

ABSTRACT: This article is the result of a systematic study based in methodologies, techniques and research strategies of History and Social Anthropology. It starts with the documentary mobilization and everyday experience among a group of revelers who practice the Folia de Reis by Carlos Chagas (MG). The objective was to analyze the motivational nucleus present in the performance of revelers. The mythical narrative embodied in the "passadas" during the "mythical experience" (mitopráxis), the "Festa da Folia" stood out. From there it was possible to analyze the symbolic elements linked to biblical events related to the birth of the baby Jesus. Such elements appeared in the revelers' performances during the Folia ritual. This ritual recalls biblical passages and also promotes benefits, benefits and devotions to the Saint. The Folia de Reis, in addition to a religious festival, an intangible heritage, is also a type of ritual linked to the cosmology of the Catholic religious system practiced in the region studied for over a century. 


\section{Introdução}

É comum observar em muitas regiões brasileiras o hábito de montar Árvore de Natal e Presépio como parte das decorações natalinas que marcam no calendário católico o fim de cada ano. Nesta época é celebrado o nascimento de Jesus Cristo, dia 25 de dezembro. Estas duas práticas acima mencionadas elucidam elementos simbólicos presentes no sistema religioso católico. Um fato curioso, e o que mais nos interessa neste momento, é a relação simbólica que se pode traçar entre as comemorações natalinas e a festa-ritual realizada em comemoração ao dia de Santos Reis (6 de janeiro). É neste mesmo dia, convencionado entre muitos religiosos, que se realiza a desmontagem das árvores de natal e dos presépios.

A Folia de Reis remete à uma história mítica com eventos bíblicos relacionais. A festa da Folia é um evento que comemora o dia de Santo Reis através de um ritual que rememora uma passagem bíblica narrada em Matheus 2:1. Esta, retrata a "visita de três magos vindos do oriente" e guiados por uma estrela cadente até a manjedoura aonde nascera o menino Jesus.

$\mathrm{Na}$ cosmologia cristã o nascimento de Cristo (o "salvador") representa um núcleo simbólico que constitui parte importante do sistema religioso ${ }^{1}$ católico. Ainda, ao longo do tempo, com a incorporação do cristianismo no Brasil, algumas das crenças e costumes católicos se popularizaram e se misturaram as crenças advindas de culturas ibéricas, africanas e indígenas. É neste contexto intercultural que buscaremos analisar a Folia de Reis enquanto um "ritual" capaz de emergir de uma mitopráxis ${ }^{2}$ vinculada à uma narrativa performatizada sazonalmente por grupos de "Foliões" 3 entre os dias 24 de dezembro a 6 de janeiro (com algumas raras exceções).

A prática da Folia de Reis (também conhecida como "charolas" ou "companhias") é considerada um símbolo do folclore brasileiro (BRANDÃO, 1977; PASSOS, 2007). Segundo Instituto Estadual do Patrimônio Histórico e Artístico de Minas Gerais, a "Festa de Reis" tem origem ibérica e chegou no Brasil por volta do século XVIII (IEPHA-MG, 2019). A Folia representa simbolicamente a peregrinação dos três reis magos Belchior, Baltazar e Gaspar para presentear o recém-nascido Menino Jesus. A prática da Folia de Reis pode ser observada em diversas regiões brasileiras, contextualizadas, atualizadas e rearranjadas a partir das motivações dos foliões organizadores das "passadas" 4.

Em 2016, o lepha-MG através de uma plataforma on line ${ }^{5}$ iniciou o cadastramento das Folias de Reis e dos grupos de Foliões do estado de Minas Gerais (MG). Inicialmente, em um período de

\footnotetext{
${ }^{1}$ Ver sobre em Clifford Geertz (1989) "a religião como um sistema cultural”.

2 Para Marshall Sahlins (1990) este conceito refere-se a ideia de "mito" enquanto uma "vivência mítica" (práxis) através da prática do "ritual".

${ }^{3}$ Categoria nativa utilizados pelos interlocutores para se referir àqueles que articulam e fazem a Folia acontecer.

${ }^{4}$ Expressão nativa dita pelos interlocutores da pesquisa para se referir a realização da Folia, quando ela é guiada e vai passando nas casas de algumas pessoas ao longo da sua passada.

${ }^{5}$ www.iepha.mg.gov.br
} 
seis meses, foram cadastradas 834 Folias praticadas em aproximadamente 255 municípios mineiros. $\mathrm{Na}$ atualização da plataforma datada de 26 de setembro de 2019 observamos o registro de 1836 Folias praticadas em mais de 300 municípios (as vezes mais de uma Folia registrada no mesmo município).

Para se ter uma ideia da abrangência da prática da Folia de Reis no estado de Minas Gerais é possível observar no cadastramento sua ocorrência em: Belo Horizonte, registrada nas localidades do Bairro Paula IV e do Bairro Aparecida; Em Bom Despacho, advindas das localidades São Vicente, Fátima, Rosário, Córrego Arado, entre outras; No município de Patos de Minas com Folias cadastradas em localidades como Distrito Sede e Povoado Santana de Patos; Já na região da Zona da Mata Mineira, foram cadastradas as Folias de Visconde do Rio Branco, da localidade Piedade Acima e da comunidade Maçambará (zona rural). Os municípios que tiveram mais Folias de Reis cadastradas foram Uberaba com 106 grupos de foliões e João Pinheiro com 34 registros.

Nesse sentido, observando sua extensão e a padronização de suas múltiplas recorrências, analisaremos o fenômeno da Folia de Reis como ritual que possui um núcleo motivacional comum, mesmo sofrendo pequenas variações devido aos rearranjos nos interesses e características dos foliões mestres (seus principais articuladores). Logo, os santos, as promessas, as vestimentas e cânticos tornam-se algo particular de cada grupo de foliões. Um exemplo disso pode ser verificado nos dados fornecido pelo levantamento do lepha-MG, que mostra as variações na devoção dos Santos homenageados durante a Folia: Aproximadamente 883 Folias cadastradas indicaram ser devotas de Santo Reis, 255 declararam ser devotas de São Sebastião, 193 ao Menino Jesus e, ainda, 130 indicaram ser devotas do Divino Espírito Santo. Diante da abrangência dessa prática ritual no estado de MG, em janeiro de 2017 a Folia de Reis é tombada como Patrimônio Cultural Imaterial de Minas Gerais pelo Conselho Estadual do Patrimônio Cultural (CONEP).

Considerando o levantamento realizado pelo lepha-MG como um pano de fundo quantitativo, buscaremos aprofundar algumas de nossas análises e reflexões por meio de um certo mergulho etnográfico. A partir desse movimento traçar alguma compreensão acerca da "vivência mítica" acionada pelo mito gestado dentro de um sistema religioso e recontado pela Folia de Reis. Assim, para analisar a Folia de Reis e compreender a dimensão de sua mitopráxis buscou-se por evidências observadas e experiênciadas junto a um grupo de foliões originários da região do Vale do Mucuri, nordeste mineiro (moradores de Carlos Chagas).

Para subsidiar nossas investigações foi realizada uma revisão da literatura existente, um levantamento de outros estudos realizados sobre a prática da Folia de Reis (dados secundários) e ainda de dados produzidos durante nosso trabalho de campo durante a "passada" (ou "giro") da Folia de Reis de Carlos Chagas (MG). Também foram realizadas entrevistas com alguns foliões, registros de vídeos e fotografias da ocorrência da Festa da Folia.

O arcabouço teórico-metodológico que nos ajudou com as análises partiu da mobilização de alguns conceitos e ideias cunhadas pela Antropologia, a saber: a noção de performance ${ }^{6}$, ritual,

\footnotetext{
${ }^{6}$ Utilizaremos itálico para ressaltar categorias/conceitos analíticos e palavras estrangeiras, e as "aspas" para destacar categorias nativas, falas/narrativas, menção e/ou citação direta à autores.
} 
sistema simbólico de significação e mitopráxis. Tais categorias analíticas ajudaram a compreender através de uma dimensão histórica, cultural e religiosa, as motivações para a prática do ritual religioso, de dimensão folclórica e patrimonial.

\section{A Folia de Reis como um "ritual religioso"}

Victor Turner $(1969 ; 1974)$ afirma, baseado nas ideias do antropólogo norte americano Lewis Henry Morgan (1818 - 1881), que existem dois grupos principais de rituais: os "sagrados" e os "seculares". Os primeiros, estão relacionados com os aspectos religiosos presentes na vida social, os segundos remetem à traços relacionados a vida ordinária como, por exemplo, àqueles relacionados aos "rituais de passagem" como é o caso do casamento e da festa de aniversário. $\mathrm{Na}$ ocasião trataremos de analisar um tipo de ritual religioso (ou "ritual sagrado"). Este ritual se manifesta inspirado nas vivências cotidiana das pessoas, tendo por objetivo responder aos "dramas da vida social". Neste sentido, o "ritual" apresenta em sua lógica central, "o simbólico que representa memórias ligadas a uma área de vida em comum" (TURNER, 1974, p.119).

Para Turner (1920-1983) o conceito de ritual deveria ser pensado em consonância ao de performance. Para ele, os "rituais" são "memórias em ação" (idem.) que ligam o indivíduo ao coletivo por meio de representações simbólicas capazes de lidar com situações difíceis. Nesse sentido, a performance desempenhada por cada agente no momento ritualizado deve ter a capacidade de interligar o imaginário coletivo às consciências individuais (1974, p.119). Logo, para imaginarmos uma saída para o dilema de se compreender "ritual" e sua importância para as análises de processos sociais e da consolidação de uma prática social sazonal por meio de sua "eficácia simbólica", como diria Lévi-Strauss (1908-2009), deve-se ter em mente que o "simbólico" (mito) é além de tudo pragmático. O que significa dizer que o "ritual" possibilita a "vivência mítica" por ele acionada (SAHLINS, M. 1990, p.9).

A centralidade do "ritual" neste estudo deve-se aos recursos teórico-metodológicos que foram aqui arranjados para nos ajudar a elucidar algumas motivações para a prática da Folia de Reis de Carlos Chagas (MG). Como esse "ritual" se desenvolve e como podemos observar, documentar e analisá-lo? Até que ponto o "ritual" nos permite observar uma gênese simbólica das formas de "ser", "estar" e de dar "sentido" para uma realidade compartilhada entre pessoas de um determinado grupo social? O "ritual", trata-se de um fenômeno social (re)produtor de referenciais simbólicos e pragmáticos por meio de elementos culturais/sociais aderentes numa força agregadora, como por exemplo, a própria sociabilidade que mantem o vínculo entre aqueles adeptos da Folia de Reis.

O "ritual" se destaca das práticas cotidianas. Normalmente se destaca devido ao seu tempo de ocorrência, sua sazonalidade e traços preparativos para o momento ritual, o momento em si e os efeitos dele no social. Destaca-se por ser um momento de ocorrência de performances específicas motivadas por um sistema próprio de significação (TAMBIAH, 1985; PEIRANO, 2001).

A análise do "ritual" torna-se um importante artifício metodológico para compreendermos o social através de suas relações, narrativas e ações que expressam seus significados culturais e religiosos. Peirano (2001) enfatiza que "dizer" é "fazer", ao passo que, "fazer" também é "dizer" no "contexto ritual". Tal fenômeno ajudaria, por exemplo, a perceber como acontece a relação entre o 
"mito" e o "rito" dentro de um processo ritual. Para essa autora, além do "ritual" apresentar traços específicos, ele não é algo exclusivamente extraordinário à vida social por ser produzido pelo próprio cotidiano das pessoas. Logo, os rituais são produzidos pelas práticas sociais e guiados por uma "memória coletiva" sustentada pela sua própria realização. Nesses termos, o "ritual religioso" não estaria ligado apenas às questões relativas à "magia" ou ao "sagrado", mas também, às esferas políticas e econômicas de uma determinada sociedade.

\section{A Folia de Reis no plural e no singular: a mobilização dos agentes em redes de foliões}

A Folia de Reis trata-se de uma prática religiosa advinda de um sincretismo religioso apropriado por um catolicismo popular e híbrido (PASSOS, 2011) que passou a fazer parte do folclore brasileiro (BRANDÃO, 1977; CHAVES, W. 2014). A Folia de Reis tem "suas origens ibéricas" e foi "incorporada" no Brasil no século XIX, estimulada inicialmente por padres jesuítas passou a ser inserida a outros elementos religiosos locais (RODRIGUES \& CORDEIRO, 1995. p.52). A Folia, pensada para além do tempo presente, remete à uma narrativa mítica que perpassou a história da expansão do cristianismo em nosso país. Esse ritual religioso atravessou o atlântico e foi aderido por vários grupos sociais espalhados pelo interior do pais através das gerações. Em Minas Gerais a prática da Folia a princípio se dera no contexto da zona rural, depois migrou-se com as pessoas para as pequenas cidades e seus entornos (ARAUJO, 2019).

A Festa da Folia acontece normalmente no período que vai do dia 25 de dezembro a 6 de janeiro (RODRIGUES \& CORDEIRO, 1995), todavia estas datas podem variar conforme as necessidades e interesses daqueles que articulam as "passadas da Folia". Tal fato foi observado em Carlos Chagas e, também, em outras localidades mencionadas por algumas pesquisas e estudos consultados.

A imersão e aproximação de um dos pesquisadores junto aos Foliões de Carlos Chagas possibilitou a realização do trabalho de campo ${ }^{7}$. A partir daí foram realizadas observações participante, entrevistas diretas e indiretas, e ainda, foram registradas impressões e anotações em blocos de notas, diários, registros fotográficos e de vídeo. Devido ao fato de um dos pesquisadores ser músico e residir próximo da região investigada, foi possível uma rápida integração no grupo de foliões interlocutores do estudo. Logo, foi possível estabelecer um maior diálogo e interação com os foliões mestres da Folia. Acompanhou-se a preparação, planejamento, articulação e a realização da "passada da Folia" na comunidade de Carlos Chagas (MG) durante o desenvolvimento da pesquisa de campo.

Por meio dos foliões percebeu-se que a prática da Folia foi passada de geração a geração, garantindo a existência de uma memória coletiva ao longo do tempo e do espaço. Também, foi

\footnotetext{
${ }^{7}$ A pesquisa foi realizada através do Departamento de História da UFV e durante o período de 2013 e 2014, estiveram vinculadas ao Procultura, um programa de apoio à cultura e à arte, em consonância com a Política Nacional de Extensão, que concedeu bolsas para estudantes de graduação. Além disso, contou com um pesquisador voluntário que acompanhou o processo, tratamento e análise dos dados. Estas ações possibilitaram a produção de uma monografia (UFV, 2015) e uma dissertação (UFSJ, 2019).
} 
possível verificar que o ritual da Folia foi motivado por narrativas míticas advindas do sistema religioso católico, envolvendo preces, pagamento de promessas, devoção à Santos padroeiros e a performance que rememora uma passagem bíblica. As Folias de modo geral, e também a de Carlos Chagas, remetem à elementos simbólicos presentes em uma memória coletiva capaz de acionar a prática ritual. Esta, convertida em uma "vivência" relacionada a um "mito de origem" e de renovação da prosperidade. Ou seja, um "rememorar [de] suas narrativas fundantes, mas também atualizá-las e revivê-las, por meio de seus símbolos, ritos, gestos, cantos, ritmo e cor" (RODRIGUES \& CORDEIRO, 1995. p. 57).

Com base nas narrativas dos foliões interlocutores é possível dizer que a prática da Folia já existia antes deles nascerem. Com base na bibliografia consultada e nos relatos dos "foliões" interlocutores de Carlos Chagas percebe-se que a ocorrência da Folia na região existe há pelo há pelo menos 100 anos, (RODRIGUES \& CORDEIRO, 1995; ARAUJO, 2019). Entretanto, essa prática social se conforma através de arranjos, articulações e relações sociais específicas que pintam a particularidade dentro do núcleo simbólico comum motivacional, revivida a cada época.

A Folia remete à elementos simbólicos que expressam a particularidade de um sistema cultural religioso que fornece identidade ao ethos de grupo. Tal manifestação social, entendida para além dos aspectos religiosos que fundamentam a "festa da Folia", pode ser compreendida por meio de seu próprio "processo ritual" - acionando uma eficácia simbólica capaz de (re)organizar e coordenar os dramas e conflitos vivenciados no cotidiano das pessoas. Essa dimensão extravasada ao campo do sagrado, pois elenca elementos advindos das relações de trabalho, de lazer, de contraprestações e da manutenção dos laços de sociabilidade.

\section{A "passada" da Folia de Reis de Carlos Chagas}

Os protagonistas deste estudo residiam na região do Vale do Mucuri, pertencentes as classes populares e habitantes em casas localizadas numa zona fronteiriça entre o urbano e o rural. Nessa localidade há tempos se pratica a Folia de Reis. Nesse contexto se insere a Folia de Ademar', Altamiro, Lídio, Leopoldino, Sarapião, Dona Kelé9 ${ }^{9}$ Reinaldo, Abilo, Zé Preto, Antônio, Dé Ramalho e Joaquim Caboclo ${ }^{10}$. Estas pessoas ${ }^{11}$ trabalhavam no trato da terra, como vaqueiros, pedreiros e ou serviços gerais quando na cidade. Alguns, como Kelé, Ademar e Zé Preto se autodeclaram para nós como sendo descendentes de africanos, enquanto outros, disseram "ter sangue indígena", como é o caso de Joaquim Caboclo.

Foi possível verificar que a atuação de Zé Preto e Zé Cumprido tornara-se fundamentais na difusão dessa prática na cidade de Carlos Chagas (MG). Zé Cumprido, já falecido, era pai do cantador Ademar, um importante agente articulador da Folia. Joaquim Caboclo e Dona Kelé foram pioneiros na rede social de cantadores da Folia de Reis na região. Segundo nos conta Ademar (2013), cantador da Folia desde os seus onze anos de idade, seu pai "nasceu em 1922, migrado para

\footnotetext{
${ }^{8}$ Falecido em janeiro de 2019.

${ }^{9}$ Falecida em 10 de maio de 2020 com 92 anos.

${ }^{10}$ Faleceu no dia 05 de fevereiro de 2019.

${ }^{11}$ Priorizou-se por respeitar seu nomes ou seus apelidos perante a comunidade.
} 
região em 1939. Viveu no Vale do Mucuri até 1990, ano de seu falecimento". Zé Preto (2013) alega ter "aperfeiçoado a prática com Zé Cumprido, por volta dos anos de 1939, quando sua família mudara para a região".

Ademar, aponta que a "passada da Folia" é motivada devido sua fé e devoção ao Santo, pois este é capaz de zelar pela proteção da saúde individual e coletiva. Segundo nos conta, o momento da Folia é para agradecimentos as graças alcançadas, para o pagamento de promessas e, ainda, para abençoar a plantação e a colheita de alimentos. Ou melhor, nas palavras do próprio folião, a Folia serve para "[...]sarar alguém, para uma roça dar melhor fruto, né(?) Tá entendendo(?) Tudo isto motivava, ou também fé normal das pessoas, no santo, ou por que tinha ajudado ele numa época, ou que veio de tradição, de outros lugares, isto tudo" (trecho de entrevista).

Ainda, questionados sobre a prática da Folia de Reis, nossos interlocutores, ressaltaram que não existe apenas uma Folia, mas que "são várias folias". Ademar, Zé Preto e dona Kelé afirmaram que cada comunidade e/ou grupo de foliões expressam sua devoção com base no seu Santo protetor. Logo, este fato é prova de que a realização desse ritual religioso não é estanque nem está congelado no tempo e espaço, ele se manifesta sempre de modo atualizado às motivações e expectativas daqueles que articulam diretamente a Folia, ou seja, através dos foliões-mestres organizadores dos repertórios, vestimentas, melodias, cantos e agentes importantes na devoção ao Santo homenageado.

Durante o trabalho de campo realizado na cidade de Carlos Chagas (MG) entre os anos de 2013 e 2014 foi possível acompanhar a movimentação dos agentes em torno da articulação da Festa da Folia em devoção a São Sebastião. A "passada" da Folia aconteceu na zona rural, nos entornos da cidade à uns dez quilômetros do centro urbano. Tal evento contou com o apoio da prefeitura que ajudou no translado dos foliões e seus instrumentos. Além dos adereços e objetos sagrados portados pelo grupo de foliões, estes levavam roupas e utensílios que thes poderiam ser úteis durante a "passada" ritual da Folia. A Folia aconteceu entre os dias 13 a 14 de janeiro de 2014, data incomum de ocorrer mas que foi ajustada ao tempo do grupo. Na bagagem os cantadores levavam seus instrumentos, os dançarinos suas véstias, o mestre sua sabedoria e mais a bandeira guia até o final do percurso por algum fiel escudeiro.

Amanheceu o dia 13 de janeiro de 2014. Logo de manhã os Foliões ensaiaram um rito conhecido como "polistas" ou "paulistas e batuques". Esse aquecimento já servia de introdução para o início das "passadas". O rito consistia na formação ritmada de duplas de Folião, formando seis, dispostas lado a lado; enquanto tocam violão, viola, pandeiro, tambor e alguns batiam as palmas de modo ritmado enquanto outros cantavam, dançavam e se entrecruzavam de um lado a outro. Durante a performance o público envolto olhava atentamente. Havia iniciado a "passada". A bandeira bordada a mão trazia a imagem do santo São Sebastião circulada por uma moldura colorida e decorada com fitas nas cores dos detalhes das vestimentas dos foliões e dançarinos, imprimindo uma certa uniformidade. Nesse primeiro dia caminhou-se um trajetos de alguns poucos quilômetros, passando em cinco propriedades rurais, pernoitando o grupo de foliões na casa de seu Zé Firmino.

No outro dia, os Foliões chegaram empolgados ao sítio de onde partiria novamente a "passada", a casa do seu Zé e Josefina. Carregar a bandeira do Santo para os Foliões praticantes da 
Folia é algo muito importante. Para eles, São Sebastião é o Santo que representa toda a luta para preservar a paz e a prosperidade, pois a imagem do Santo remete à uma figura heroica.

Ademar, Altamiro, Lídio, Leopoldino, Sarapião, Zé Preto, Joaquim Caboclo (os cantadores e músicos) vestiam um lenço vermelho no pescoço, que segundo nos contou Reinaldo (2013), filho de Zé Preto, representava sua devoção à São Sebastião. Isso porque muitas vezes a devoção à uma determinada entidade é também demarcada por meio das corres do lenço. Sendo este um dos elementos particulares, além das melodias e músicas tocadas durante as "passadas" de cada Folia.

A bandeira da Folia, construída a mão, bordada e pintada cuidadosamente a imagem de São Sebastião, colorida com detalhes em vermelho e tons de azul, segue abrindo o caminho estrada afora. Enquanto isso os músicos seguem-na acompanhando e dançando junto com os três dançarinos foliões que executam suas performances específicas. Enquanto isso, o mestre cantador da Folia canta versos em agradecimento, sobre as preces, sobre o pagamento das promessas e devoção ao Santo protetor.

Quando a bandeira surgia ao longe na estrada, os moradores já corriam para receber a Folia. Na visita eram realizados cantos e rezas específicas, o mestre da Folia sugeria a reza, outra música e muita dança. O mestre abençoa os moradores da casa e suas colheitas, enquanto isso os donos da casa ofertavam dinheiro, comida, bebida e ou algum outro bem material. Depois àqueles que receberam a visita da bandeira a acompanhava até a próxima casa. Não existe uma regra para que a casa que recebe a Folia deve ser a que carrega a bandeira, mas isso ocorre com frequência aqui.

Em dois dias foi percorrido o trajeto que circulou entre as comunidades, Marques I e II. Ao todo foram visitadas dose casas. Na maioria das casas, haviam quadros e imagens de santos. Era comum encontrar quadro de Jesus Cristo afixado nas paredes das casas visitadas, além de imagens de Nossa Senhora Aparecida e de São Sebastião. A expressão da devoção aos santos e religiosidade católica era notada na sala de visitas, logo na entrada observava-se as imagens e os quatros mencionados acima. As pessoas destas comunidades receberam a Folia com muita alegria, devoção e respeito. Alguns tradicionalmente dão dinheiro ou outra "prenda", que posteriormente serve como investimento na próxima "festa da Folia".

Nota-se que a Folia neste contexto é uma prática que se atualiza no tempo e tem a capacidade de fortalecer os vínculos sociais, a memória e identidade de grupo por meio das "passadas", ou melhor, através das visitas sustentadas por um complexo sistema religioso ligado aos elementos simbólicos do cristianismo e da vida das pessoas. Sendo assim, a Folia interpretada aqui como um ritual seria uma poderosa força de mobilização social em torno do sagrado buscando por resolução dos dramas sociais presentes na vida cotidiana.

\section{Algumas considerações finais}

No início deste artigo mencionamos uma certa "coincidência" estabelecida entre o dia de Santo Reis e o dia convencionado para se desmontar a Árvore de Natal (6 de janeiro), ambos eventos estavam relacionados a narrativa mítica contida neles, e representada simbolicamente também no 
Presépio: relacionados ao nascimento de Jesus Cristo. A relação dos eventos e esquemas simbólicos possuem um fundamento bíblico dentro do sistema religioso católico.

Ainda, como observado durante a "passada da Folia" de Carlos Chagas, a representação da narrativa bíblica motiva a ocorrência da "Festa" ritual. O Santo carregado junto a bandeira da Folia é aquele à quem se devota o mestre da Folia, a comunidade que ele representa, e daquele que financia a "festa". A mitopráxis aparece no fato da "peregrinação" dos três reis vindo do oriente em busca do salvador menino jesus, acionando sua eficácia simbólica nas performances das "passadas". Desse modo, o "mito" só 'conseguiu operar no real' junto ao público participante do ritual a partir do momento que estes puderam vivenciá-lo. Logo, é através dos momentos ritualizados que o "sagrado" encontra sustentação na prática ordinária das pessoas, garantindo assim a resolução de seus "dramas sociais".

É esse espírito de coisas que movem os foliões, conectando a vida ordinária e as dificuldades e superações com benções e proteções de Santos católicos. O pagador de promessas é o "festeiro" de onde parte e retorna a bandeira depois do giro das "passadas". Durante a Folia de Reis, a devoção ao Santo é revelada através das danças, cantigas, brincadeiras, contos, ritos e símbolos participantes. A "passada da Folia" culmina na centralidade ritual da Folia, momento simbólico auge da materialidade presente nas performances dos foliões que: cantam, dançam e carregam a bandeira da Folia até as casas que aceitam (ou já aceitaram previamente) receber a visita. Assim, o evento observado representa uma cosmologia própria mobilizada por meio da vivência mítica expressada durante a ocorrência da Folia de Reis em Carlos Chagas (MG).

A prática da Folia revela uma capacidade de mobilização coletiva, reforçando e criando laços de sociabilidade. Isso se dá tanto no momento do ritual quanto antes e depois dele, constituído com base em uma memória coletiva e sua relação direta com a vida ordinária dos mestres da Folia. Estes, desempenham o papel de articuladores da "festa de Reis" e são portas vozes do enredo e ritos presente nas performances. Eles realizam a produção e celebração da Folia em diálogo com os donos das casas visitadas, de modo que durante as "passadas" seja possível encontrar nas casas alimentação e agasalho suficiente para todos, e lugar para pernoitar caso necessário.

Considerando o processo histórico, a narrativa mítica, a transmissão de uma memória coletiva de geração para geração, a prática da Folia de Reis a partir das experiências de Ademar, Joaquim Caboclo e Zé Preto, ajudam a compor a vivência mítica através do ritual. A Bandeira representa simbolicamente a estrela que na passagem bíblica guiou os três reis magos até a manjedoura onde nascera Jesus (representada pelo Presépio), rememorando a passagem bíblica durante a "passada da Folia" - a mitopráxis. 


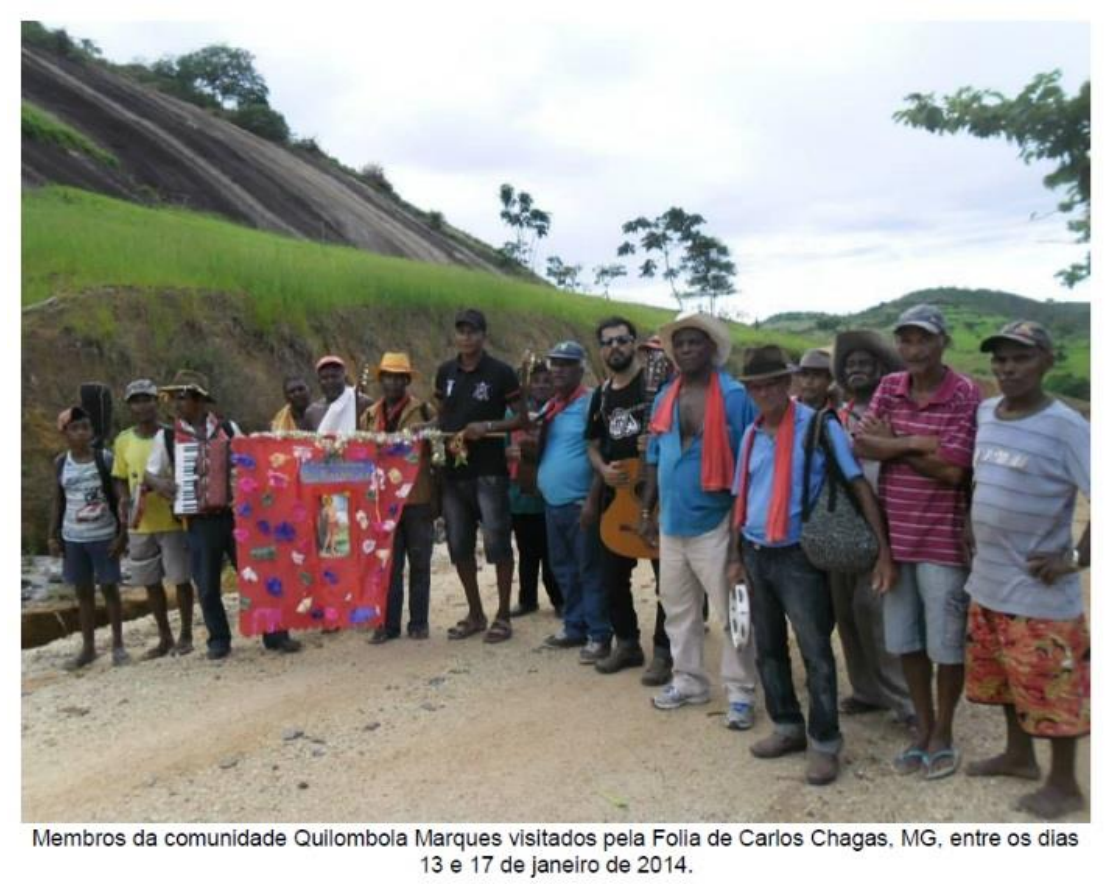

\section{REFERÊNCIAS}

ABREU, Andréa Vicente Toledo. O cultivo de sonhos: uma cartografia das políticas públicas de cultura da zona da mata mineira. Dissertação (Mestrado em Ciências Sociais). Universidade Federal de Juiz de Fora, Juiz de Fora, 2010.

ALTAMIRO. Mangalô. Resgate e Divulgação da Cultura Regional Mineira. 2013. Entrevista concedida a André Luiz Ribeiro de Araújo na cidade de Carlos Chagas, MG.

ARAÚJO, A. L. Ribeiro. A Folia de Reis de Carlos Chagas: Uma abordagem sobre a Tecnoligização da Cultura. Dissertação do Programa de Pós-Graduação Interdisciplinar em Artes, Urbanidades e Sustentabilidade da Universidade Federal de São João del-Rei, MG, 2019. p.122.

BíBLIA SAGRADA. Edição Claretiana. Tradução do Centro Bíblico Católico. São Paulo: Ave Maria, 1989.

BRANDÃO, Carlos Rodrigues. O que é folclore. Ed: Brasilense S. A. São Paulo, 1984.

CABOCLO, Joaquim. Mangalô: Resgate e Divulgação da Cultura Regional Mineira. 2013. Entrevista concedida a André Luiz Ribeiro de Araújo na cidade de Carlos Chagas, MG. No Registro de Identidade, este senhor consta como nascido em 1916. Atualmente estaria com idade de 104 anos.

CHAVES, Wagner Diniz. Canto, voz e presença: uma análise do poder da palavra cantada nas folias norte-mineiras. Mana 20(2): 249-280, 2014.

CHAVES, Christine Alencar. "Introdução ». In : . A Marcha Nacional dos Sem Terra. Rio de Janeiro : NuAP, Relime-Dumará, (disponível em : http://nuap.etc.br/colecao-nuap/a-marcha-nacionaldos-sem-terra/), pp. 13-31.

COSTA, Jean Henrique. Indústria Cultural e o forró eletrônico no Rio Grande do Norte / Jean Henrique Costa. - Natal, RN, 2012. 309 f.; il. Tese (doutorado) - Universidade Federal do Rio Grande do Norte.

ELIADE, Mircea. O sagrado e o profano. [1957] Trad. Rogério Fernandes. Ed. Martins Fontes. São Paulo. 1992.

GEERTZ, Clifford. A Interpretação das Culturas. Rio de Janeiro: LTC, 1989. 

34, maio 1999.

Os usos da diversidade. In: Horizontes Antropológicos, Porto Alegre, ano 5, n10, pág. 13-

GOLOVATY, Ricardo Vidal. Cultura popular: saberes e práticas de intelectuais, imprensa e devotos de Santos Reis, 1945-2002 / Ricardo Vidal Golovaty. - Uberlândia, 2005. 180f.: il. Orientador: Newton Dângelo. Dissertação (mestrado) - Universidade Federal de Uberlândia, Programa de PósGraduação em História.

INSTITUTO DO PATRIMÔNIO HISTÓRICO E ARTÍSTICO NACIONAL. Inventário nacional de referências culturais: manual de aplicação. Apresentação de Célia Maria Corsino. Introdução de Antônio Augusto Arantes Neto. - Brasília, 2000. Conteúdo: Referências culturais: base para novas políticas de patrimônio / Cecília Londres; Como ler o INRC / Antônio Augusto Arantes Neto.

KELÉ, Dona. Mangalô: Resgate e Divulgação da Cultura Regional Mineira. 2013. Entrevista concedida a André Luiz Ribeiro de Araújo na cidade de Carlos Chagas, MG.

LARAIA, Roque de Barros. Cultura: um conceito antropológico. 19.ed. Rio de Janeiro: Jorge Zahar Ed.,2006.

LEAL, Alessandra Fonseca. \& LEAL, Erika Adriana. Políticas públicas, culturas populares e patrimônio cultural imaterial: meios e alternativas. RAEGA (Espaço Geográfico em análise) 26 (2012), p.247-269 www.geografia.ufpr.br/raega/ Curitiba, Departamento de Geografia UFPR ISSN: 2177-2738 - 2012.

MARQUES, Carlos Eduardo. Os Marques do Boqueirão. Belo Horizonte, MG: Fino Traço, 2012.

MARTINS, Marcos Lobato. Ocupação e desflorestamento numa área de fronteira: Vale do Mucuri, MG - 1890 a 1950. Revista de História Regional 15(1): 40-77, Verão, 2010.

MATTOS, Sônia Missagia. Comunidade Quilombola Marques (Carlos Chagas - MG/ Sônia Missagia Mattos). - Goiânia: Ed. Da UCG, 2008.

OUROFINO, João Venâncio M. De. A folia de reis em São Braz de Minas: A migração, as transformações locais, e o imaginário religioso. Universidade de Brasília - UNB Instituto De Ciências Humanas Programa De Pós-Graduação Em História Área De Concentração: História Cultural, 2009.

PEIRANO, Mariza. «Rituais como estratégia analítica e abordagem etnográfica »; "A análise antropológica dos rituais". In : __ . O dito e o feito. Ensaios de Antropologia dos rituais. Rio de Janeiro : Relume Dumará, 2001, pp. 7-40. Disponível em : http://nuap.etc.br/livros/

PEIRANO, Mariza. Rituais ontem e hoje. Rio de Janeiro, Jorge Zahar Ed., 2003.

PRETO, ZÉ. Mangalô: Resgate e Divulgação da Cultura Regional Mineira. 2013. Entrevista concedida a André Luiz Ribeiro de Araújo na cidade de Carlos Chagas, MG.

RIBEIRO, Eduardo Magalhães. Lembranças da terra - histórias do mucuri e jequitinhonha. Ed: SEGRAC, 1995.

RIBEIRO, Eduardo Magalhães, 1955 - Estradas da vida: terra e trabalho nas fronteiras agrícolas do Jequitinhonha e Mucuri, Minas Gerais / Eduardo Magalhães Ribeiro. Belo Horizonte: Editora UFMG, 2013.

REINALDO. Mangalô: Resgate e Divulgação da Cultura Regional Mineira. 2013. Entrevista concedida a André Luiz Ribeiro de Araújo na cidade de Carlos Chagas, MG. 
RODRIGUES, Cláudio Eduardo \& CORDEIRO, Cristina Xavier. O sentido mítico das folias de reis do vale do mucuri. 1995.

SAHLINS, M. Cultura e Razão Prática. Rio de Janeiro. Jorge Zahar Editor, 2003. Illhas de História.Raio de Janeiro. Jorge Zahar Editor, 1990.

SANCHIS, Pierre. "A caminhada ritual". Religião e Sociedade, (9), 1983, pp. 15-26, junho.

SCHECHNER, Richard. 2006. "What is performance". In: Performance studies: an introduction, second edition. New York \& London: Routledge, 2006, p. 28-51. (Há tradução em português)

SILVA, F. Weder. Colonização, política e negócios: Teófilo Benedito Ottoni e a trajetória da Companhia do Mucuri (1847-1863). In: dissertação de mestrado apresentada ao Programa de pósgraduação em História da UFOP. Mariana, 2009.

SOUZA, Ademar Rodrigues de. Mangalô: Resgate e Divulgação da Cultura Regional Mineira. 2013. Entrevista concedida a André Luiz Ribeiro de Araújo na cidade de Carlos Chagas, MG.

TAMBIAH, Stanley. "The Magical Power of Words". Man (New Series), 1968 3(2): 175-208.

TURNER, Victor W. O processo Ritual: estrutura e anti-estrutura. In. Victor Tuner. Coleção Antropologia. Petrópolis: Vozes, pp.1974. 13-60.

TURNER, Victor.The anthropology of performance. In: The Anthropology of performance. Nova York: PAJ Publications, 1987 p. 72-98.

VICTORASSO, Pedro Henrique. As Folias de Reis na historiografia brasileira. XVII Simpósio Nacional de História, Conhecimento histórico e diálogo social. NR Natal. 22 a 26 de julho de 2013. ANPUH Brasil. 